Gut, 1986, 27, 450-451

Case report

\title{
Intestinal perforation in Wegener's granulomatosis
}

\author{
J GERAGHTY, I R MACKAY, AND D C SMITH
}

From the Victoria Infirmary, Glasgow

SUMmARY Wegener's granulomatosis is a disease characterised by a necrotising vasculitis and granulomatous inflammation. The localised form involves the upper and/or lower respiratory tracts while in the commoner generalised form there is a widespread necrotising vasculitis and renal involvement. Intestinal involvement, which may be severe, ${ }^{1}$ has been detected at necropsy in $24 \%$ of cases. ${ }^{2}$ Gastrointestinal symptoms are uncommon, however, none being mentioned in a recent series of 87 cases. ${ }^{3}$ There has been only one reported case of intestinal perforation secondary to Wegener's granulomatosis. ${ }^{4}$ We report a case of small and large bowel perforations in a patient with Wegener's granulomatosis.

\section{Case history}

A 46 year old man presented with lethargy, weight loss, and polyarthralgia of four weeks duration and a four day history of frank haemoptysis. Physical examination was normal but chest radiograph showed cavitating lesions in the right lower and left upper zones as seen in the figure. On admission his ESR was $120 \mathrm{~mm} / \mathrm{h}$, haemoglobin $10.7 \mathrm{~g} / \mathrm{dl}$, platelets $548 \times 10^{9} / 1$, Rheumatoid factor $1 \cdot 320$, Anti-nuclear factor $-v e$. Transaminases, alkaline phosphatase, and gamma glutanyl transpeptidase became mildly raised. Sputum and bronchial aspirate were negative for malignant cells, AAFB, and fungal pathogens. Bone marrow examination showed changes of secondary anaemia. Liver biopsy was normal. Urinalysis revealed microscopic haematuria and proteinuria of $630 \mathrm{mg} /$ day but creatinine clearance was normal.

Four weeks later he developed nasal and palatal ulceration, iridocycitis, purpuric skin lesions and ischaemic right second, third, and fourth toes. Biopsy of his nasal septum showed a necrotising vasculitis typical of Wegener's granulomatosis and he was started on cyclophosphamide $2 \mathrm{mg} / \mathrm{kg} /$ day and prednisolone $1 \mathrm{mg} / \mathrm{kg} / \mathrm{day}$. Three days after starting treatment he developed abdominal pain and

Address for correspondence: Dr I R Mackay, Division of Surgery. Victoria Informary. Glasgow G42 9TY.

Received for publication 16 August 1985.

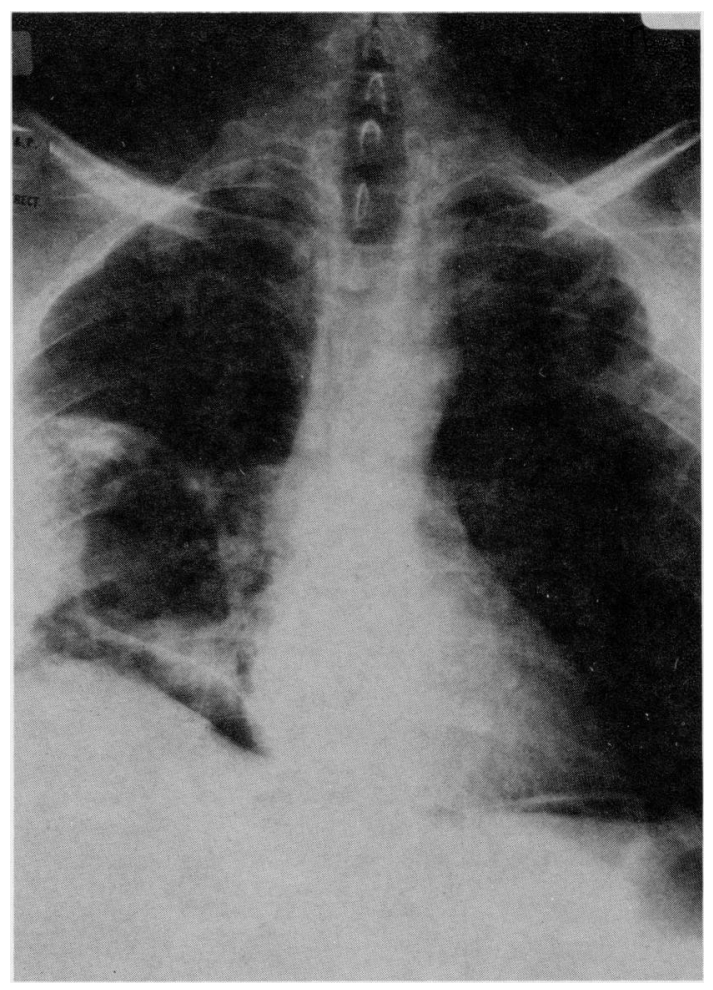

Figure Chest radiograph after perforation. Note the cavitating lung lesions and free gas. 
signs of peritonism. Chest radiograph showed free air under the diaphragm (Figure). At laparotomy there was inflammation of the entire small bowel with numerous areas of necrotic ulceration. The inflammation was most marked in the terminal ileum where there were three perforations. These perforations were oversewn in two layers. Treatment with cyclophosphamide and steroids was continued but after initial good progress he developed septic shock five days postoperatively and despite artificial ventilation, died 48 hours later.

Post mortem examination showed two large perforations of the ascending colon and multiple punched out ulcers of the distal small bowel and proximal large bowel. The three oversewn perforations were intact. Granulomata were found in the lungs, spleen, and prostate. Histology again confirmed the presence of a necrotising vasculitis although no vasculitis was seen in the bowel wall.

\section{Discussion}

This case fulfils the diagnostic criteria of Wegener's granulomatosis. The question to be answered here is whether the perforations were due to Wegener's granulomatosis alone or whether immunosuppressive therapy was a causal factor. Intestinal perforation has been reported as a rare complication of immunosuppressive treatment in patients after renal transplantation and in leukaemics. ${ }^{56}$ Azathioprine and prednisolone were most commonly incriminated. The one previously reported case of intestinal perforations in Wegener's granulomatosis ${ }^{4}$ occurred in the terminal ileum five days after treatment with azathioprine and prednisolone had been started. After surgery the patient survived on treatment with cyclophosphamide and prednisolone and developed no further perforations. It has been shown that Wegener's granulomatosis may involve the intestinal tract and it may well be that immunosuppressives exacerbate already existing areas of ulceration but a larger series will be needed to provide a definite answer.

\section{References}

1 Haworth SJ, Pusey CD. Severe intestinal involvement in Wegener's granulomatosis. Gut 1984; 25: 1296-9.

2 Walton EW. Giant-cell granuloma of the respiratory tract (Wegener's granulomatosis). Br Med J 1958; 1: 265-70.

3 Fauci AC, Hayes BF, Katz P, Wolff SM. Wegener's granulomatosis: prospective clinical and therapeutic experience with 85 patients for 21 years. Ann Intern Med 1983; 98: 76-85.

4 McNabb WR, Lennox MS, Wedzicha JA. Small intestinal perforation in Wegener's granulomatosis. Postgrad Med J 1982; 58: 123-5.

5 Demling RH, Salvatierra O, Belzer FO. Intestinal necrosis and perforation after renal transplantation. Arch Surg 1975; 110: 251-3.

6 Matolo NM, Garfinkle SE, Wolfman EF, Jr. Intestinal necrosis and perforation in patients receiving immunosuppressive drugs. Am J Surg 1976; 132: 753-4. 